\title{
An atlas on biomarkers for Alzheimer's disease
}

\author{
Marta Martínez-Rivera * \\ Hospital Álvarez-Buylla, Mieres, Spain \\ ${ }^{*}$ Correspondence: maildemarta@gmail.com \\ Edited by: \\ Manuel Menéndez-González, Hospital Álvarez-Buylla, Spain \\ Reviewed by: \\ Oscar Arias-Carrion, Hospital General Dr. Manuel Gea González, Mexico
}

Keywords: Alzheimer, biomarker, dementia, mild cognitive impairment, atlas, differential diagnosis, book review, treatment

\author{
A book review on \\ Atlas on Biomarkers for Alzheimer's disease \\ Edited by Menéndez González, M., M-Y Books, 2011, ISBN: 978-1-44772-356-1
}

The search of methods to ease the diagnosis of Alzheimer's disease (AD) as early as possible is in the center of attention. Such methods (biomarkers) are a range of blood or CSF tests on one hand, and several types of neuroimaging scans on the other. Biomarkers are going to be included not only in the neuroscience research area but also in the diagnosis process with a practical application in the next years. The potential for these biomarkers to serve diagnostic purposes of $\mathrm{AD}$ has been highlighted in the proposed diagnostic criteria for preclinical $\mathrm{AD}$ from an NIH/NIA working group (Sperling et al., 2011). In these criteria, biomarkers are defined in terms of whether they reflect $A \beta$ deposition, tau deposition, or signs of neuronal injury. Markers of $A \beta$ deposition include both positron-emission tomography (PET) evidence of $A \beta$ deposition and cerebrospinal fluid (CSF) measures of lower $A \beta 42$ levels, using a variety of specific ligands. Markers of tau accumulation include CSF measures of increased total tau or phosphorylatedtau (p-tau). Together with low CSF A $\beta 42$, elevated CSF tau provides a high likelihood of progression to $\mathrm{AD}$ in patients with MCI (mild cognitive impairment). A third group of biomarkers reflect biochemical changes related to processes such as cell death, synaptic damage, oxidative stress, or inflammation that may be part of the cascade of events that mediate damage, or the response to damage, in AD. This is a field, as many others in science, that suffers a quick evolution every year; and the moment of apply biomarkers in clinical practice is coming. It is necessary to make the clinical community aware of these scientific advances in a clear and concise manner, as well as counting with references that can guide our clinical practice with a consensus point of view.

Many of the images coming both from laboratory and neuroimaging studies are very illustrative. These images, accompanied by a short description, can perfectly explain the main results and usefulness of each biomarker. And this is just what the Atlas created by Dr Manuel Menéndez does (Menéndez González, 2011). The objective of this book is to summarize the most important studies made in this field. Few publications have systematically compiled results on this topic and none as an atlas. The book starts clarifying concepts as "biomarker", "mild cognitive impairment" and other preclinical conditions, and then focus on classification and description of all biomarkers for AD. A collection of imagines selected from outstanding research studies are provided for both laboratory and neuroimaging biomarkers. Finally the author finishes with a chapter on the rational use of biomarkers for $\mathrm{AD}$ in the clinical setting.

Readers will be interested in this publication because it allows reviewing the current status of research at the time that visualizing outstanding results easily. The possibility of coming across an optimal and well done review of biomarkers for $\mathrm{AD}$ is crucial not only for expertees, but also for the large public seeking to make a first approach to the world of biomarkers for AD. Such an easy to use manual, with the purpose to make the broad and often confusing biomarkers discussion surrounding $\mathrm{AD}$ accessible to a wider audience, notably in the clinic, is invaluable. The contents seem adequate, and Dr. Menéndez has a well-established track record in this field that ensures the quality of the final product, and therefore I am certain the scientific contents are solid. Overall it is a solid and timely proposal, at a competitive price range, which I am sure will make an impact where it matters the most, in the clinic with patients.

\section{REFERENCES}

Menéndez González, M. (Ed.). (2011). Atlas on Biomarkers for Alzheimer's disease. M-Y Books. ISBN: 978-1-44772-356-1

Sperling, R. A., Aisen, P. S., Beckett, L. A., Bennett, D. A., Craft, S., Fagan, A. M., et al. (2011). Toward defining the preclinical stages of Alzheimer's disease: recommendations from the National Institute on Aging-Alzheimer's Association workgroups on diagnostic guidelines for Alzheimer's disease. Alzheimers Dement. 7, 280-292. doi: 10.1016/j.jalz.2011.03.003

Received: 12 May 2013; accepted: 04 September 2013; published online: 08 November 2013.

Citation: Martínez-Rivera $M$ (2013) An atlas on biomarkers for Alzheimer's disease. Front. Aging Neurosci. 5:54. doi: 10.3389/fnagi.2013.00054

This article was submitted to the journal Frontiers in Aging Neuroscience.

Copyright (c) 2013 Martinez-Rivera. This is an openaccess article distributed under the terms of the Creative Commons Attribution License (CC BY). The use, distribution or reproduction in other forums is permitted, provided the original author(s) or licensor are credited and that the original publication in this journal is cited, in accordance with accepted academic practice. No use, distribution or reproduction is permitted which does not comply with these terms. 